\title{
Significance of Tumor-Associated Macrophages in the Clinical Therapy of Breast Cancer
}

\author{
Yufan Lu ${ }^{1}$, Xiaoyu Shi ${ }^{1}$, Junqing Liang ${ }^{2}$ \\ ${ }^{1}$ School of Graduate, Inner Mongolia Medical University, \\ Huhehaote, Inner Mongolia Province, China \\ ${ }^{2}$ Department of Breast Surgery, Inner Mongolia Autonomous Region Cancer Hospital, \\ Huhehaote, Inner Mongolia Province, China
}

\begin{abstract}
Breast cancer is one of the cancers with the highest death rate in women worldwide, there is a trend of rising incidence and younger age. Tumor-associated macrophage (TAM) is an essential part of the inflammatory infiltration and is associated with adverse clinical outcomes of breast cancer. TAM can change its phenotype according to the signals of the tumor microenvironment (TME), killing tumor cells or promoting tumor cell growth and metastasis. In recent years, TAM has become a hot spot for breast cancer therapy. This article reviews the theoretical basis and strategies of targeted TAM therapy.
\end{abstract}

Keywords: Tumor-associated macrophage, Cancer immunity, Cancer immunotherapy, Breast cancer.

\section{Introduction}

Breast cancer is the most prevalent cancer among women worldwide, with Chinese cases accounting for about $12 \%$ of all new cases and $10 \%$ of all breast cancer-related deaths[1]. Breast cancer overall mortality declines year by year, but still accounts for more than $14 \%$ of cancer deaths in women. Mainly due to the cancer's high metastases, high recurrence rates, and resistance to therapy[2]. In recent years, the role of TME in inducing tumor cell growth, distant metastasis, and resistance to systemic therapy has been widely recognized. Tumor-associated macrophage (TAM) is also part of TME. TAM can change its phenotype according to the signals of the surrounding microenvironment, and can destroy tumor cells or promote tumor cell growth and metastasis[4]. Moreover, in pre-clinical breast cancer models, TAM can induce resistance to various types of treatments such as chemotherapy, radiotherapy, etc. In mouse models, altering the phenotype of macrophages by inhibiting their recruitment or re-induction can enhance therapeutic efficacy and improve prognosis[5,6,7]. In a meta-analysis including more than 260 breast cancer patients, higher TAM infiltration in the primary tumor predicts poorer clinical outcomes and lower treatment rates[8]. Among the many types of breast cancer treatment strategies, TAM is the next therapeutic target that can be discovered and has great potential in clinical treatment. This article will review the targeted TAM therapy based on the theoretical basis of TAM function.

\section{TAM in Breast Cancer}

\subsection{Classification and Functions of TAM}

Macrophages are an innate immune cell type that play important roles in immune defense, physiological homeostasis, and regulation of inflammatory responses[9]. Depending on the source, macrophages can be broadly classified into the following three categories, including monocyte-derived tumor-associated macrophages, tissueresident macrophages, and myeloid-derived suppressor cells. TAM is usually divided into M1(anti-tumor) and M2 (pro-tumor) phenotypes according to function, which are the two extremes of the continuous functional state[10]. Classically activated M1 type macrophages migrate to inflamed tissues to produce nitric oxide (NO), tumor necrosis factor $\alpha(\mathrm{TNF}-\alpha)$ and interleukin2 (IL-2), IL-13, IL-26 and other effective inflammation response factor to kill tumor cells. and mediate antitumor immune effects. Alternately activated M2 macrophages induce T lymphocytes (Tregs) and T-helper 2 cell (Th2)-mediated immune protective responses by secreting anti-inflammatory cytokines, but lack cytotoxic function. M2 type macrophages have tissue trophic functions and can stimulate angiogenesis by secreting vascular endothelial growth factor (VEGF), and transforming growth factor $\beta$ (TGF- $\beta$ ) to promote tumor growth and spread[11]. It is worth noting that the majority of TAMs in the breast cancer microenvironment are of the M2 phenotype, which often adds to the complexity of tumor therapy[12].

\subsection{Recruitment of Macrophages to Breast Cancer}

TAM is a vital part of the inflammatory infiltration of breast cancer[13]. TAM recruitment is the key to the initiation of subsequent effects, and chemokine ligand2 (CCL2), CCL3, and CCL5 play an important role in the recruitment of TAM. CCL2 synthesized by tumor and stromal cells can induce macrophages into the breast cancer microenvironment and polarize into M2 macrophages to promote tumor progression[14]. CCL2 can directly act on CCR2 on the vascular endothelial cell membrane, chemotactic endothelial directional cell movement. Chemokine CCL2 and its receptor CCR2 participate in tumor progression by recruiting TAM. CCL2 has now been demonstrated in a preclinical animal model to promote distant metastasis of breast cancer[15]. Activated CCL2-CCR2 axis promotes CCL3 production in macrophages and further enhances bone metastasis from breast cancer[16]. Breast cancer cells are able to express and secrete CCL5 and act on the proliferation, migration and infiltration of tumor cells in an autocrine manner[17]. The expression of monocyte chemotactic protein 1 (MCP-1)/ CCL2 in breast cancer interstitial cells is positively correlated with the abundance of TAMs in tumor tissue, while the expression of CCL5 is the opposite[18]. It has been reported that CCL5 can change the function of TAM in colorectal cancer, converting M1 type to M2 type[19]. 
Colony stimulating factor1(CSF-1), vascular permeability factor (VPF), and vascular growth factor (VEGF) also play an important role in the recruitment of macrophages. In mouse breast cancer models, the expression of CSF-1 is related to the increased infiltration of CSF-1R-expressing macrophages and affects the prognosis. VPF can attract monocytes into the tumor. In multiple tumor types, increased secretion of VEGF correlates with increased macrophage infiltration[20,21]. In addition, hypoxia is also a factor that cannot be ignored. The study found that NRP-1 is an indispensable key link for inducing TAMs into hypoxic regions. This induced response is dependent on SEMA 3A, plexin-A1/A4, VEGF receptors and VEGFR-1[22].

Macrophages can be recruited from blood, spleen, bone marrow, and resident progenitor cells, and have different phenotypes and proportions in tumor progression[23,24]. It is also worth noting that the loss of resident macrophages in breast cancer models is accompanied by an increase in monocyte-derived macrophages[25].

\subsection{Differentiation and Maturation of TAM in Breast Cancer}

Differentiation, polarization, and maturation of TAM are regulated by TME signaling, leading to the heterogeneity of cell populations. TAM differentiates into M2 type under induction of colony stimulating factor1(CSF-1).IL-3, IL-4, IL-10 and transforming growth factor $\beta(\mathrm{TGF}-\beta)$. By supporting tumor cell growth, metastasis, angiogenesis and spread, it shows tumor-promoting functions. TAM differentiates into an M1-like phenotype driven by interferon $\gamma($ IFN- $\gamma$ ), tumor necrosis factor $\alpha$ (TNF- $\alpha$ ) and lipopolysaccharide (LPS). By migrating into tissues to generate reactive oxygen species and nitric oxide reactants, while inducing Th1 pro-inflammatory responses (IL-1, IL-6, IL-12, TNF- $\alpha$ ), it exerts powerful cytotoxic and anti-proliferative effects[26,27,28].

\section{Pro-Tumor Functions of TAM in Breast Cancer}

\subsection{Promotion of Tumorigenesis}

There is evidence that TAM can promote tumor cell proliferation and spread by secreting factors such as CCL2, IL- $1 \alpha$, IL-6, and TNF- $\alpha$ [29]. At the same time, TNF- $\alpha$ can activate nuclear factor $\kappa \mathrm{B}(\mathrm{NF}-\kappa \mathrm{B})$ in tumor cells to avoid irreversible necrosis of tumor cells and enhance the invasive ability of tumor cells[30]. Tumor cells can recruit and activate M2 type macrophages to produce CCL18. In humanized mouse models, both anti-GM-CSF and anti-CCL18 can reverse the epithelial-mesenchymal transition (EMT) state of breast cancer cells and inhibit tumor metastasis[31]. TAM can further reduce the expression level of estrogen and progesterone receptors in breast cancer cells, increasing the expression of urokinase lasminogen activator receptor (UPAR) and Ki67, thereby participating in the prognosis of breast cancer[32].

\subsection{Promotion of Angiogenesis}

Tumor angiogenesis is an intergal factor in tumor generation and progression. Angiogenesis is a very complex process, involving tumor cells, vascular endothelial cells, inflammatory immune cells and many other cells. TAM activates VEGF-A by producing matrix metalloproteinase 9 (MMP9) to increase the secretion of VEGF. VEGF binds to the corresponding receptors on the vascular endothelium to promote the proliferation and metastasis of endothelial cells, thereby inducing angiogenesis[33]. TAM also produces TGF- $\alpha$, TGF- $\beta$, epidermal growth factor (EGF) and plateletderived growth factor (PDGF) further to support the growth of blood vessels[34]. TAM can also promote angiogenesis by producing CCL18[35]. In addition, a group of monocytes expressing endothelial cell tyrosine kinase receptor 2 (Tie2) are TAM derived from human peripheral blood and tumors, which can promote tumor angiogenesis[36]. TAM can express hypoxia-inducible factor1 (HIF-1) andHIF-2 to deal with the hypoxic environment of tumors, and promote tumor angiogenesis by regulating the expression of a series of genes, thereby supporting the growth of tumor cells[37].

\subsection{Promotion of Metastasis}

TAM plays a significant role in tumor progression and metastasis by producing matrix metalloproteinase (MMP) and urokinase (uPA)[38]. By activating the cascade reaction of matrix degradation, it makes the penetration of tumor cells easier and affects the invasion and metastasis of breast cancer. In a breast cancer study, direct visualization of macrophages by intravital multiphoton imaging showed that TAM positively contributes to reperfusion of intratumoral blood vessels[39]. A study based on the MMTV-PyMT mouse breast cancer model found that decreased CSF-1 gene expression resulted in decreased TAM, which in turn decreased tumor progression[40]. CXCL1 secreted by TAM promotes breast cancer cell migration, spread, invasion and can lead to epithelial-mesenchymal transition[41]. The Ets-2 transcription factor in TAM has an irreplaceable role in promoting primary tumor metastasis and angiogenesis after tumor metastasis[42]. IL-4 has also been reported to activate cathepsin activity in TAMs to promote breast cancer invasion[43].

\subsection{Reducing Productive Antigen Presentation}

TAM can affect the efficiency of antigen-presenting cells and reduce the expression level of pro-inflammatory factors in TME, thereby affecting the activation of $\mathrm{T}$ cells and the immune response mediated by them[44]. It has been reported that TAM with high expression of tumor-friendly features such as IL-4R and SR-A has low level of MHCII expression. However, TAM subgroups characterized by low expression of MHCII are less effective in antigen presentation[45,46]. Compared with traditional dendritic cells (DC), macrophages have limited ability to process antigens, and the antigen presentation ability of TAM is greatly restricted[46.47]. At the same time, the high expression of IL-10 and TNF- $\alpha$ in TAM can also inhibit the expression of IL-2 and the efficiency of DC antigen presentation, further inhibiting the immune response of tumors[48].

\subsection{Suppression of T Cell Function}

The formation of an immunosuppressive microenvironment is 
one type of immune escape mechanism. TAM inhibits the migration of NK cells, thereby suppressing immunity. Tregs induce apoptosis, cytolysis, and local immune tolerance in effector cells and play a role in autoimmunity and metabolic inflammation. CCL22 and CCL20 can induce immunesuppression by recruiting Tregs[49]. In addition, CCL17, CCL18, CCL22, IL-4, IL-10, IL-12, TGF- $\beta$, NO, H2O2 and prostaglandin E2 (PGE2) all have the ability to inhibit $\mathrm{T}$ cell function[50,51]. Programmed death receptor 1 (PD-1), a member of the immunoglobulin superfamily, is an important immunosuppressive molecule. TAM can highly express ligands that bind to PD-1 molecules, which further inhibits the immune function of $\mathrm{T}$ cells[52]. By blocking the B7-H1/4 protein on TAM, the efficiency of macrophage- mediated $\mathrm{T}$ cell activation can be increased[52,53].

\section{Significance of TAM in Breast Cancer Therapy}

\subsection{Clinical Significance of TAM in Breast Cancer}

High TAM expression is associated with poor clinical outcomes in breast cancer patients, and high TAM infiltration is an independent marker of poor breast cancer prognosis, especially in $\mathrm{HR}+$ breast cancer patients[54.61]. In a meta-analysis, it was found that high invasiveness of TAM predicts poor survival in breast cancer patients[55]. In the analysis of 11,000 cases of breast tumors, it was found that among the immune cells associated with poor clinical prognosis and low therapy rates in ER+ breast cancer, TAM expression is most significantly associated[56,57]. The study found that inpatients with ER+ breast cancer, a higher proportion of M1TAMpredictd higher pathological complete response rate (pCR), prolonged disease-free survival (DFS) and overall survival (OS), and had a certain positive correlation[57]. TAM is associated with breast cancer metastasis and recurrence, and it has been confirmed that signaling pathways dominated by NF- $\kappa \mathrm{B}$ and IL- 6 can induce endocrine therapy resistance in ER+ breast cancer cells[58]. In an analysis of 40 patients with HER2+ breast cancer treated with trastuzumab, high expression of M1TAM (iNOS+) was positively associated with improved survival, while high expression of M2TAM (CD163+) was positively associated with poorer clinical outcomes[59]. In addition, a high proportion of M1TAM and CD8+ $\mathrm{T}$ cell binding can significantly improve survival. Both could be combined therapy markers for predicting patients' ability to remain disease-free after weaning off trastuzumab[59]. While low-expressing TAM and high-expressing CD8+ T cell populations predict better recurrence-free survival (RFS)[6].

\subsection{TAM Obstructs to Chemotherapy and Immunotherapy}

Preclinical studies found increased TAM infiltration in tumors of paclitaxel-treated mice, and the addition of cathepsin inhibition improved long-term survival in mice[62]. In ER+ and HER2- clinical samples, compared with tamoxifensensitive samples, CD163+ macrophage population infiltration was higher in tamoxifen-resistant samples, and EGFR expression was increased, which was positively correlated with tumor volume, metastasis[63]. In addition, when anti-CSF-1R treatment, TAM was depleted, and then
CD8+ T cells successfully infiltrated the TME, enhancing immune resistance against tumors[64]. In preclinical animal models, combined anti-PD-1 therapy induces potent anti-tumor immune responses when anti-CSF-1R therapy has limited efficacy[65].

\subsection{Targeting TAM for Clinical Anti-cancer Treatment}

In view of the multifaceted roles of TAMs in tumorigenesis and progression, there are a variety of targeted therapy strategies. One strategy is to prevent macrophages from producing tumor-promoting effects. Reducing the recruitment of macrophages by inhibiting factors such as CCL2, CCL3, CCL5. By blocking the "immune checkpoint suppression" of macrophages (CD47/SIRP1 $\alpha$, PD-1/PD-L1, MHC I/LILRB1 and CD24/Siglec-10), inhibiting the production of TGF- $\beta$ or VEGF to inhibit the promotion of macrophages tumor activity [60.66-69]. Improved therapy by depleting macrophages with inhibitors of CCL2, CSF-1 and CSF-1R, which has been validated in multiple tumor types[6,70] However, as a monotherapy CCL2 inhibitor, when the treatment is stopped, it will drive tumor metastasis in the manner of IL-6 and VEGF[71]. The strategy of blocking CD47 has also achieved certain results[72]. However, in the syngeneic model, CD11b + DCs also express SIRP- $\alpha$, and the effect of CD47 blockers to promote antitumor immunity depends on the cytoplasmic induction of tumor DNA by DCs[73,74].

CSF-1R is an intersection of TAM-targeted therapeutic strategies, and high expression of CSF-1 or CSF-1R is significantly associated with tumor progression and mortality[75]. Blockade of CSF-1R reduces TAM infiltration, which in turn increases CD8 $+\mathrm{T}$ cell infiltration, improves response to therapy and reduces resistance to therapy[6,76]. In a study, combination therapy with pexcitanib and paclitaxel improved treatment resistance and found decreased TAM density in solid tumors[77]. However, some studies have also shown that the proportion of immunosuppressive TAMs decreased after the administration of emetuzumab, but did not show a therapeutic benefit in combination with paclitaxel[78]. It is worth noting that studies have also found that inhibition of CSF-1R expression can promote the progression of breast cancer[79]. The combined use of anti-CSF-1R drugs and $\mathrm{T}$-cell function-enhancing drugs can significantly improve the clinical prognosis of patients. Combination therapy of anti-CSF-1R with a CD40 agonist activates transient hyperactivation of macrophages, which is sufficient to generate a potent antitumor immune response in ICB therapy-resistant advanced tumors[80]. When combined with PARP inhibitors, it can improve OS[81]. Preclinical studies of breast cancer treated with CSF-1R signaling antagonists combined with carboplatin demonstrated enhanced tumor control and reduced metastasis. Importantly, blocking CSF-1 signaling enhanced cytotoxic $\mathrm{T}$ cell infiltration in anti-tumor immunity and chemotherapy[6].

Another strategy is to convert tumor-promoting TAM into tumor-resistant TAM. The efficacy of CD40 agonists, PI3K $\gamma$ inhibitors, CD47 inhibitors, and class IIa HDAC inhibitors have all been validated in a variety of treatment regimens and have been suggested to reduce the metastatic spread of primary breast cancer[82,83,84,85]. In addition, it includes Bruton tyrosine kinase (BTK) inhibitors, Toll-like receptor 
(TLR) agonists, signal transduction and activator of transcription 3 (STAT3) inhibitors, interleukin 1 receptor (IL1RA) inhibitors and inhibitory leukocytes Immunoglobulin-like receptor 2 (LILRB2) inhibitors can convert TAM to M1 phenotype[86,87,88,89,90].

By depleting inhibitory TAM or activating anti-tumor TAM strategies, combined with immune or radiotherapy, it has great application value for the clinical treatment of patients. When targeting TAM, the ability of the therapeutic agent to reach the metastatic site should also be considered. Studies have found that in mouse breast cancer models, local pulmonary administration is more effective than oral administration in inhibiting CSF1R, and it can significantly increase the M1/M2 ratio at low doses[91].

\section{Future Perspectives}

TAM has a high proportion of infiltrating immune cells and is an integral part of TME. TME affects the phenotype of TAM, prompting TAM to be more biased towards M2. TAM participates in the whole process of breast cancer evolution by promoting tumor cell proliferation, tumor angiogenesis, and affecting tumor microenvironment immunity. Therefore, it has become the critical point of breast cancer treatment. By blocking the tumor-promoting function of TAM and promoting the transformation of TAM into an anti-tumor phenotype, two main treatment strategies have achieved remarkable results in a number of studies. However, the multiple effects of TAM, combined with the complexity of TME, make it challenging to achieve satisfactory results for single-target TAM therapy. This challenge requires a multi-faceted targeted strategy to deal with.

Preclinical studies show that targeted TAM therapy can improve the efficacy of immunotherapy and address the limitations of traditional therapy. Despite the clinically superior prognosis and some considerable early trial results, the best treatment method has not yet been determined[92,93]. It is worth noting that although macrophage infiltration is relatively high in tumor types such as ovarian cancer, pancreatic cancer, and mesothelioma, it is not clear whether these reflect the people who receive the greatest benefit from targeted therapy. Besides we are not yet sure which type of treatment strategy (depletion or reprogramming) should be used for which tumor type. We still need more clinical data to provide reliable evidence for the choice of treatment options. Studies have shown that in the pancreatic tumor model, anti-CD40 antibodies are toxic to mice before combined with gemcitabine[94]. Therefore, the type and priority of drugs in the treatment plan are extremely important, which requires more studies to achieve the maximum efficacy with the smallest dose. Given the complexity of targeted TAM therapy, we need more pre-clinical and post-clinical experimental data. Targeted TAM therapy still has excellent potential.

\section{References}

[1] Fan L, Strasser-Weippl K, Li JJ, St Louis J, Finkelstein DM, Yu KD, Chen WQ, Shao ZM, Goss PE. Breast cancer in China. Lancet Oncol. 2014 Jun;15(7): e279-89.
[2] Torre LA, Bray F, Siegel RL, Ferlay J, Lortet-Tieulent J, Jemal A. Global cancer statistics, 2012. CA Cancer J Clin 2015; 65: 87-108.

[3] Qian BZ, Pollard JW. Macrophage diversity enhances tumor progression and meta stasis. Cell 2010; 141: 39-51.

[4] Salmaninejad A, Valilou SF, Soltani A, Ahmadi S, Abarghan YJ, Rosengren RJ, Sahebkar A. Tumor-associated macrophages: role in cancer development and therapeutic implications. Cell Oncol (Dordr). 2019 Oct;42(5):591-608.

[5] Xu M, Liu M, Du X, Li S, Li H, Li X, Li Y, Wang Y, Qin $\mathrm{Z}$, Fu YX, Wang S. Intratumoral Delivery of IL-21 Overcomes Anti-Her2/Neu Resistance through Shifting Tumor-Associated Macrophages from M2 to M1 Phenotype. J Immunol. 2015 May 15; 194(10): 4997-5006.

[6] DeNardo DG, Brennan DJ, Rexhepaj E, Ruffell B, Shiao SL, Madden SF, et al. Leukocyte complexity predicts breast cancer survival and functionally regulates response to chemotherapy. Cancer Discov 2011; 1: 54-67.

[7] Shiao SL, Ruffell B, DeNardo DG, Faddegon BA, Park CC, Coussens LM. TH2-po-larized CD4(+) T cells and macrophages limit efficacy of radiotherapy. Cancer Immunol Res 2015; 3: 518-25.

[8] Zhang Q, Liu L, Gong C, Shi H, Zeng Y, Wang X, et al. Prognostic significance of tumor-associated macrophages in solid tumor: a meta-analysis of the literature. PLoS One 2012;7:e50946.

[9] Okabe Y, Medzhitov R. Tissue biology perspective on macrophages. Nat Immunol. (2016) 17: 9-17.

[10] DeNardo DG, Ruffell B. Macrophages as regulators of tumour immunity and immunotherapy. Nat Rev Immunol. 2019 Jun; 19(6): 369-382.

[11] Jayasingam SD, Citartan M, Thang TH, Mat Zin AA, Ang KC, Ch'ng ES. Evaluating the polarization of tumor-associated macrophages into M1 and M2 phenotypes in human cancer tissue: technicalities and challenges in routine clinical practice. Front Oncol. (2019)9: 1512.

[12] Mantovani A, Sozzani S, Locati M, Allavena P, Sica A. Macrophage polarization: Tumor-associated macrophages as a paradigm for polarized M2 mononu clear phagocytes. Trends Immunol. 2002; 23: 549-55.

[13] De Palma M, Lewis CE. Macrophage regulation of tumorresponses to anticancer therapies. Cancer Cell. (2013) 23: 277-86.

[14] Tsuyada A, Chow A, Wu J, Somlo G, Chu P, Loera S, et al. CCL2 mediates cross-talk between cancer cells and stromal fibroblasts that regulates breast cancer stem cells. Cancer Res. (2012) 72:2768-79.

[15] Li X, Yao W, Yuan Y, Chen P, Li B, Li J, Chu R, Song H, Xie D, Jiang $X$, Wang $H$. Targeting of tumourinfiltrating macrophages via CCL2/CCR2 signalling as a therapeutic strategy against hepatocellular carcinoma. Gut. 2017 Jan; 66(1): 157-167.

[16] Kitamura T, Qian BZ, Soong D, Cassetta L, Noy R, Sugano G, et al. CCL2-induced chemokine cascade promotes breast cancer metastasis by enhancing retention of metastasis-associated macrophages. J Exp Med. (2015) 212: 1043-59. 
[17] Soria G, Ben-Baruch A. The inflammatory chemokines CCL2 and CCL5 in breast cancer. Cancer Lett. 2008 Aug 28; 267(2): 271-85.

[18] Fujimoto H, Sangai T, Ishii G, Ikehara A, Nagashima T, Miyazaki M, Ochiai A. Stromal MCP-1 in mammary tumors induces tumor-associated macrophage infiltration and contributes to tumor progression. Int $\mathbf{J}$ Cancer. 2009 Sep 15; 125(6): 1276-84.

[19] Bronte V, Bria E. Interfering with CCL5/CCR5 at the Tumor-Stroma Interface. Cancer Cell. 2016 Apr 11; 29(4): 437-439.

[20] Chiaranunt P, Tai SL, Ngai L, Mortha A. Beyond Immunity: Underappreciated Functions of Intestinal Macrophages. Front Immunol. 2021 Sep 28; 12: 749708.

[21] Chen X, Hu QY, Wang M, Jia J, Teng J, Sun Y, Cheng X, Ye J, Su Y, Shi H, Chi H, Zhou Z, Liu T, Wang Z, Wan L, Qiao X, Wang F, Wu X, Yang C, Liu HL. Serum VEGF-C as an evaluation marker of disease activity in adult-onset Still's disease. Rheumatol Int. 2021 Sep 9

[22] Casazza A, Laoui D, Wenes M, Rizzolio S, Bassani N, Mambretti $\mathrm{M}$, et al.Impeding macrophage entry into hypoxic tumor areas by Sema3A/Nrp1signaling blockade inhibits angiogenesis and restores antitumor immunity. Cancer Cell. (2013) 24: 695-709.

[23] Ginhoux F, Greter M, Leboeuf M, Nandi S, See P, Gokhan S, et al. Fate mapping analysis reveals that adult microglia derive from primitive macrophages. Science. (2010) 330: 841-5.

[24] Guerriero JL. Macrophages: the road less traveled, changing anti-cancer therapy. Trends Mol Med. (2018) 24:472-89.

[25] Franklin RA, Liao W, Sarkar A, Kim MV, Bivona MR, Liu K, et al. The cellular and molecular origin of tumor-associated macrophages. Science. (2014) 344: 921-5.

[26] Tariq M, Zhang J, Liang G, Ding L, He Q, Yang B. Macrophage Polarization: Anti-Cancer Strategies to Target Tumor-Associated Macrophage in Breast Cancer. J Cell Biochem. 2017 Sep;118(9):2484-2501.

[27] Lan C, Huang X, Lin S, Huang H, Cai Q, Wan T, et al. Expression of M2-polarized macrophages is associated with poor prognosis foradvanced epithelial ovarian cancer. Technol Cancer Res Treat. (2013) 12: 259-67.

[28] Medrek C, Ponten F, Jirstrom K, Leandersson K. The presence of tumor associated macrophages in tumor stroma as a prognostic marker for breast cancer patients. BMC Cancer. (2012) 12: 306.

[29] Nandi B, Shapiro M, Samur MK, Pai C, Frank NY, Yoon C, Prabhala RH, Munshi NC, Gold JS. Stromal CCR6 drives tumor growth in a murine transplantable colon cancer through recruitment of tumor-promoting macrophages. Oncoimmunology. 2016 May 24; 5(8): e1189052.

[30] Ma CX, Yin WN, Cai BW, Wu J, Wang JY, He M, Sun H, Ding JL, You C. Toll-like receptor 4/nuclear factor-kappa B signaling detected in brain after early subarachnoid hemorrhage. Chin Med J (Engl). 2009 Jul 5; 122(13): 1575-81.

[31] Su S, Liu Q, Chen J, Chen J, Chen F, He C, Huang D, Wu W, Lin L, Huang W, Zhang J, Cui X, Zheng F, Li H, Yao H, Su F, Song E. A positive feedback loop between mesenchymal-like cancer cells and macrophages is essential to breast cancer metastasis. Cancer Cell. 2014 May 12; 25(5): 605-20.

[32] Lindsten T, Hedbrant A, Ramberg A, Wijkander J, Solterbeck A, Eriksson M, Delbro D, Erlandsson A. Effect of macrophages on breast cancer cell proliferation, and on expression of hormone receptors, UPAR and HER-2. Int J Oncol. 2017 Jul;51(1):104-114.

[33] Leek RD, Hunt NC, Landers RJ, Lewis CE, Royds JA, Harris AL. Macrophage infiltration is associated with VEGF and EGFR expression in breast cancer. J Pathol. 2000 Mar;190(4):430-6.

[34] O'Sullivan C, Lewis CE, Harris AL, McGee JO. Secretion of epidermal growth factor by macrophages associated with breast carcinoma. Lancet. (1993) 342: 148-9.

[35] Korbecki J, Olbromski M, Dzięgiel P. CCL18 in the Progression of Cancer. Int J Mol Sci. 2020 Oct 26; 21(21):7955.

[36] De Palma M, Venneri MA, Galli R, Sergi Sergi L, Politi LS, Sampaolesi M, et al. Tie2 identifies a hematopoietic lineage of proangiogenic monocytes required for tumor vessel formation and a mesenchymal population of pericyte progenitors. Cancer Cell. (2005)8: 211-26.

[37] Berlth F, Mönig SP, Schlösser HA, Maus M, Baltin CT, Urbanski A, Drebber U, Bollschweiler E, Hölscher AH, Alakus H. Validation of 2-mm tissue microarray technology in gastric cancer. Agreement of 2-mm TMAs and full sections for Glut-1 and Hif-1 alpha. Anticancer Res. 2014 Jul; 34(7): 3313-20.

[38] Hagemann T, Wilson J, Kulbe H, Li NF, Leinster DA, Charles $\mathrm{K}$, et al. Macrophages induce invasiveness of epithelial cancer cells via NF-kappa BJNK.J Immunol. (2005) 175: 1197-205.

[39] Wyckoff JB, Wang Y, Lin EY, Li JF, Goswami S, Stanley ER, et al. Direct visualization of macrophage-assisted tumorcell in travasation in mammary tumors. Cancer Res. (2007)67: 2649-56.

[40] Sapi E. The role of CSF-1 in normal physiology of mammary gland and breast cancer: an update. Exp Biol Med (Maywood). 2004 Jan; 229(1): 1-11.

[41] Wang N, Liu W, Zheng Y, Wang S, Yang B, Li M, Song J, Zhang F, Zhang X, Wang Q, Wang Z. CXCL1 derived from tumor-associated macrophages promotes breast cancer metastasis via activating NF- $\mathrm{KB} / \mathrm{SOX} 4$ signaling. Cell Death Dis. 2018 Aug 29; 9(9): 880.

[42] Zabuawala T, Taffany DA, Sharma SM, Merchant A, Adair B, Srinivasan R, et al. An ets2-driven transcriptional program in tumor-associated macrophages promotes tumor metastasis. Cancer Res. (2010) 70:1323-33.

[43] Gocheva V, Wang HW, Gadea BB, Shree T, Hunter KE, Garfall AL, Berman T, Joyce JA. IL-4 induces cathepsin protease activity in tumor-associated macrophages to promote cancer growth and invasion. Genes Dev. 2010 Feb 1;24(3):241-55.

[44] Cha YJ, Koo JS. Role of Tumor-Associated Myeloid Cells in Breast Cancer. Cells. 2020 Jul 27;9(8):1785.

[45] Movahedi K, Laoui D, Gysemans C, Baeten M, Stange G, Vanden Bossche $\mathrm{J}$, et al. Different tumor microenvironments contain functionally distinctsubsets of macrophages derived from Ly6C (high) monocytes. Cancer Res. (2010) 70:5728-39. 
[46] Quatromoni JG, Eruslanov E. Tumor-associated macrophages: function, phenotype, and link to prognosis in human lung cancer. Am J Transl Res. (2012) 4:376-89

[47] Reeves E, James E. Antigen processing and immune regulation in the response to tumours. Immunology. (2017) 150:16-24.

[48] Schülke S. Induction of Interleukin-10 Producing Dendritic Cells as a Tool to Suppress Allergen-Specific T Helper 2 Responses. Front Immunol. 2018 Mar 19; 9: 455.

[49] Liu J, Zhang N, Li Q, Zhang W, Ke F, Leng Q, et al. Tumor-associated macrophages recruit CCR6+ regulatory $\mathrm{T}$ cells and promote the development of colorectal cancer via enhancing CCL20 production in mice. PLoS ONE. (2011) 6: e19495.

[50] Chen Y, Song Y, Du W, Gong L, Chang H, Zou Z. Tumor-associated macrophages: an accomplice in solid tumor progression. J Biomed Sci. (2019) 26: 78.

[51] Trapani JA. The dual adverse effects of TGF-beta secretion on tumor progression. Cancer Cell. 2005 Nov; 8(5): 349-50.

[52] Santoni M, Romagnoli E, Saladino T, Foghini L, Guarino S, Capponi M, Giannini M, Cognigni PD, Ferrara G, Battelli N. Triple negative breast cancer: Key role of Tumor-Associated Macrophages in regulating the activity of anti-PD-1/PD-L1 agents. Biochim Biophys Acta Rev Cancer. 2018 Jan; 1869(1): 78-84.

[53] Chen C, Qu QX, Shen Y, Mu CY, Zhu YB, Zhang XG, Huang JA. Induced expression of B7-H4 on the surface of lung cancer cell by the tumor-associated macrophages: a potential mechanism of immune escape. Cancer Lett. 2012 Apr 1; 317(1): 99-105.

[54] Leek RD, Hunt NC, Landers RJ, Lewis CE, Royds JA, Harris AL. Macrophage infiltration is associated with VEGF and EGFR expression in breast cancer. J Pathol. 2000 Mar; 190(4):430-6.

[55] Zhang QW, Liu L, Gong CY, Shi HS, Zeng YH, Wang XZ, Zhao YW, Wei YQ. Prognostic significance of tumor-associated macrophages in solid tumor: A meta-analysis of the literature. PLoS One. 2012; 7(12): e50946.

[56] Ali HR, Chlon L, Pharoah PD, Markowetz F, Caldas C. Patterns of immune infiltration in breast cancer and their clinical implications: A gene-expression-based retrospective study. PLoS Med. 2016 Dec 13;13(12): e1002194.

[57] Bense RD, Sotiriou C, Piccart-Gebhart MJ, Haanen JBAG, van Vugt MATM, de Vries EGE, Schröder CP, Fehrmann RSN. Relevance of Tumor-Infiltrating Immune Cell Composition and Functionality for Disease Outcome in Breast Cancer. J Natl Cancer Inst. 2016 Oct 13; 109(1): djw192.

[58] Castellaro AM, Rodriguez-Baili MC, Di Tada CE, Gil GA. Tumor-associated macrophages induce endocrine therapy resistance in ER+breast cancer cells. Cancers. (2019) 11: 189.

[59] Honkanen TJ, Tikkanen A, Karihtala P, Mäkinen M, Väyrynen JP, Koivunen JP. Prognostic and predictive role of tumour-associated macrophages in HER2 positive breast cancer. Sci Rep. (2019)9: 10961.

[60] Zhou J, Tang Z, Gao S, Li C, Feng Y, Zhou X. Tumor-associated macrophages: recent insights and therapies. Front Oncol. (2020)10: 188.
[61] Gwak JM, Jang MH, Kim DI, Seo AN, Park SY. Prognostic valueof tumor-associated macrophages according to histologic locations and hormone receptor status in breast cancer. PLoS ONE. (2015)10: e0125728.

[62] Shree T, Olson OC, Elie BT, Kester JC, Garfall AL, Simpson K, et al. Macrophages and cathepsin proteases blunt chemotherapeutic response in breast cancer. Genes Dev. (2011) 25: 2465-79.

[63] Xuan QJ, Wang JX, Nanding A, Wang ZP, Liu H, Lian $\mathrm{X}$, et al. Tumor-associated macrophages are correlated with tamoxifen resistance in the post-menopausal breast cancer patients. Pathol Oncol Res. (2014) 20:619-24.

[64] Peranzoni E, Lemoine J, Vimeux L, Feuillet V, Barrin S, Kantari-Mimoun C, et al. Macrophages impede CD8 T cells from reachingtumor cells and limit the efficacy of anti-PD-1 treatment. Proc Natl Acad Sci USA. (2018) 115: e4041-e50.

[65] Guerriero JL, Sotayo A, Ponichtera HE, Castrillon JA, Pourzia AL, Schad S, et al. Class IIa HDAC inhibition reduces breast tumours andmetastases through antitumour macrophages. Nature. (2017) 543: 428-32.

[66] Cassetta L, Pollard JW. Targeting macrophages: Therapeutic approaches incancer. Nat Rev Drug Discov. (2018) 17: 887-904

[67] Brown JM, Recht L, Strober S. The promise of targeting macrophages in cancer therapy. Clin Cancer Res. (2017)23: 3241-50.

[68] Poh AR, Ernst M. Targeting macrophages in cancer: from bench to bedside. Front Oncol. (2018) 8:49.

[69] Pathria P, Louis TL, Varner JA. Targeting tumorassociated macrophages in cancer. Trends Immunol. (2019) 40: 310-327.

[70] Pyonteck SM, Akkari L, Schuhmacher AJ, Bowman RL, Sevenich L, Quail DF, et al. CSF-1R inhibition alters macrophage polarization and blocks glioma progression. Nat Med. (2013) 19: 1264-72.

[71] Bonapace L, Coissieux MM, Wyckoff J, Mertz KD, Varga Z, Junt T, Bentires-Alj M. Cessation of CCL2 inhibition accelerates breast cancer metastasis by promoting angiogenesis. Nature. 2014 Nov 6; 515(7525): 130-3.

[72] Liu C, Chikina M, Deshpande R, Menk AV, Wang T, Tabib T, et al. Treg Cells promote the SREBP1-dependent metabolic fitness of tumor-promoting macrophages via repression of CD8+ $\mathrm{T}$ cell-derived interferon- $\gamma$. Immunity. (2019) 51: 381-97.

[73] Pang J, Cui J, Xi C, Shen T, Gong H, Dou L, et al. Inhibition of Poly (ADP-Ribose) polymerase increased lipid accumulation through SREBP1modulation. Cell Physiol Biochem. (2018) 49:645-52.

[74] Shrestha E, Hussein MA, Savas JN, Ouimet M, Barrett TJ, Leone S, et al. Poly (ADP-ribose) polymerase 1 represses liver $\mathrm{X}$ receptor-mediated ABCA1expression and cholesterol efflux in macrophages. J Biol Chem. (2016)291: 11172-84.

[75] Richardsen E, Uglehus RD, Johnsen SH, Busund LT. Macrophage-colonytimulating factor (CSF1) predicts breast cancer progression and mortality. Anticancer Res. (2015) 35: 865-74.

[76] Ruffell B, Chang-Strachan D, Chan V, Rosenbusch A, Ho CM, PryerN, et al. Macrophage IL-10 blocks CD8+T cell-dependent responses tochemotherapy by 
suppressing IL-12 expression in intratumoral dendriticcells. Cancer Cell. (2014) 26: 623-37.

[77] Wesolowski R, Sharma N, Reebel L, Rodal MB, Peck A, West BL, et al. Phase Ib study of the combination of pexidartinib (PLX3397), a CSF-1Rinhibitor, and paclitaxel in patients with advanced solid tumors. Therap AdvMed Oncol. (2019) 11: 1758835919854238.

[78] Gomez-Roca CA, Italiano A, Le Tourneau C, Cassier PA, ToulmondeM, D'Angelo SP, et al. Phase I study of emactuzumab single agent orin combination with paclitaxel in patients with advanced/metastatic solidtumors reveals depletion of immunosuppressive M2-like macrophages. AnnOncol. (2019) 30: 1381-92.

[79] Swierczak A, Cook AD, Lenzo JC, Restall CM, Doherty JP, Anderson RL, et al. The promotion of breast cancer metastasis caused by inhibition ofCSF-1R/CSF-1 signaling is blocked by targeting the G-CSF receptor. Cancer Immunol Res. (2014) 2: 765-76.

[80] Hoves S, Ooi CH, Wolter C, Sade H, Bissinger S, Schmittnaegel $M$, et al. Rapid activation of tumor-associated macrophages boosts preexisting tumorimmunity. J Exp Med. (2018) 215: 859-76.

[81] Mehta A, Cheney EM, Hartl C, Pantelidou C, Oliwa M, Castrillon JA, et al. Differentiating macrophages are regulated by PARP inhibitorsand can be harnessed to overcome PARP-inhibitor resistance in BRCAassociated triple-negative breast cancer. Nat Cancer. (2021). 2: 66-82.

[82] Beatty GL, Chiorean EG, Fishman MP, Saboury B, Teitelbaum UR, Sun W, et al. CD40 agonists alter tumor stroma and show efficacy against pancreatic carcinoma in mice and humans. Science. (2011) 331: 1612-6.

[83] Kaneda MM, Messer KS, Ralainirina N, Li H, Leem CJ, Gorjestani S, et al. PI3Kgamma is a molecular switch that controls immune suppression. Nature. (2016) 539: 437-42.

[84] Zhang W, Huang Q, Xiao W, Zhao Y, Pi J, Xu H, et al. Advances in Anti-Tumor Treatments Targeting the CD47/SIRP $\alpha$ Axis. Front Immunol. (2020) 11: 18.

[85] Guerriero JL, Sotayo A, Ponichtera HE, Castrillon JA, Pourzia AL, Schad S, et al. Class IIa HDAC inhibition reduces breast tumours and metastases through anti-tumour macrophages. Nature. (2017) 543:428-32.

[86] Gunderson AJ, Kaneda MM, Tsujikawa T, Nguyen AV, Affara NI, Ruffell B, etal. Bruton tyrosine kinase-dependent immune cell cross-talk drives pancreas cancer. Cancer Discov. (2016) 6:270-85.

[87] Feng Y, Mu R, Wang Z, Xing P, Zhang J, Dong L, et al. A toll-like receptor agonist mimicking microbial signal to generate tumor-suppressive macrophages. Nat Commun. (2019)10: 2272.

[88] Yin Z, Ma T, Lin Y, Lu X, Zhang C, Chen S, et al. IL-6/STAT3pathway intermediates M1/M2 macrophage polarization during the development of hepatocellular carcinoma. J Cell Biochem. (2018) 119: 9419-32.

[89] Luz-Crawford P, Djouad F, Toupet K, Bony C, Franquesa M, Hoogduijn MJ, et al. Mesenchymal stem cell-derived interleukin 1 receptor antagonist promotes macrophage polarization and inhibits $\mathrm{B}$ cell differentiation. Stem Cells. (2016) 34: 483-92.

[90] Chen H-M, van der Touw W, Wang YS, Kang K, Mai S, Zhang $\mathrm{J}$, et al. Blocking immunoinhibitory receptor LILRB2 reprograms tumor-associated myeloid cells and promotes antitumor immunity. J Clin Invest. (2018)128: 5647-62.

[91] Alhudaithi SS, Almuqbil RM, Zhang H, Bielski ER, Du W, Sunbul FS, et al. Local targeting of lung-tumorassociated macrophages with pulmonary delivery of a CSF-1R inhibitor for the treatment of breast cancer lung metastases. Mol Pharm. (2020)17: 4691-703.

[92] Nywening TM, Wang-Gillam A, Sanford DE, et al. Targeting tumour-associated macrophages with CCR2 inhibition in combination with FOLFIRINOX in patients with borderline resectable and locally advanced pancreatic cancer: A single-centre, open-label, dosefinding, non-randomised, phase $1 \mathrm{~b}$ trial. Lancet Oncol. 2016; 17(5): 651-662.

[93] Wainberg ZA et al. First-in-Human Phase 1 Dose Escalation and Expansion of a Novel Combination, Anti-CSF-1 Receptor (cabiralizumab) Plus Anti-PD-1 (nivolumab), in Patients with Advanced Solid Tumors. SITC-Meeting Abstract, O42 (2017).

[94] Byrne KT, Leisenring NH, Bajor DL \& V onderheide RH CSF-1R-Dependent Lethal Hepatotoxicity When Agonistic CD40 Antibody Is Given before but Not after Chemotherapy. J Immunol 197, 179-187. 